\title{
Assessing Exposure to Violence Using Multiple Informants: Application of Hierarchical Linear Model
}

\author{
Meichun Kuo and Beat Mohler \\ Harvard School of Public Health, Boston, U.S.A.
}

\author{
Stephen L. Raudenbush \\ University of Michigan, Ann Arbor, U.S.A.
}

Felton J. Earls

Harvard Medical School, Cambridge, U.S.A.

\begin{abstract}
The present study assesses the effects of demographic risk factors on children's exposure to violence (ETV) and how these effects vary by informants. Data on exposure to violence of 9-, 12-, and 15-year-olds were collected from both child participants $(N=1880)$ and parents $(N=1776)$, as part of the assessment of the Project on Human Development in Chicago Neighborhoods (PHDCN). A two-level hierarchical linear model (HLM) with multivariate outcomes was employed to analyze information obtained from these two different groups of informants. The findings indicate that parents generally report less ETV than do their children and that associations of age, gender, and parent education with ETV are stronger in the self-reports than in the parent reports. The findings support a multivariate approach when information obtained from different sources is being integrated. The application of HLM allows an assessment of interactions between risk factors and informants and uses all available data, including data from one informant when data from the other informant is missing.
\end{abstract}

Keywords: Assessment, multivariate analysis, exposure to violence, multiple informant.

Abbreviations: ETV : exposure to violence; HLM: hierarchical linear model; MAR: missing at random; PHDCN: Project on Human Development in Chicago Neighborhoods.

\section{Introduction}

\section{Need for Multiple Informants}

Epidemiological research on child and adolescent mental health typically uses multiple sources of information. For different standardized instruments assessing child psychopathology, parent, teacher, and child forms have been developed. Psychiatric symptoms often vary in home or school environments (Achenbach, McConaughy, \& Howell, 1987). Having different sources of information presumably helps increase the reliability and validity of assessments and helps construct a comprehensive picture of the child's behavior.

Most studies have found only low to moderate correlations between informant reports (Achenbach et al., 1987; Angold et al., 1987; Edelbrock, Costello, Dulcan, Calabro, \& Kala, 1986; Fergusson \& Horwood, 1987, 1989; Offord et al., 1996; Verhulst \& Van der Ende, 1992). The absence of strong correlations between informants suggests that these measures tap sources of variances that are not in common (Fergusson \& Horwood, 1987, 1989).

The consistency of results across informants may depend on the disorder being assessed. Lower parentchild agreement is found for affective disorders or

Requests for reprints to: Meichun Kuo, ScD, Harvard School of Public Health,1633 Tremont Street, Boston, MA 02120, U.S.A. (E-mail: mkuo@hsph.harvard.edu). internalizing symptoms than for behavior problems or externalizing symptoms (Achenbach et al., 1987; Edelbrock et al., 1986; Fitzmaurice, Laird, Zahner, \& Daskalakis, 1995; Verhulst \& Van der Ende, 1992). For affective disorders, the correlation between child and parent reporting may depend on the family structure and on parent psychopathology (Andrews, Garrison, Jackson, Addy, \& McKeown, 1993; Angold et al., 1987). Another important factor influencing the agreement is age. Parent-child agreement increases with child age, more for externalizing than for internalizing symptoms (Edelbrock et al., 1986). Time spent with the child has been supported as another factor influencing the agreement (Fitzgerald, Zucker, Maguin, \& Reider, 1994). It is questionable whether each informant measures the same constructs. Offord et al. (Offord, Boyle, \& Racine, 1989; Offord et al., 1996) suggest that child psychopathology should be conceptualized as informant-specific phenomena because the prevalence and correlates of the specific disorders vary by informant. The discrepancy in reports implies that we need to understand the factors influencing respondents' judgements of children's behavior.

\section{Methods for Analyzing Multiple Informants}

A major issue is whether the information gathered from different informants should be combined or treated separately in making specific diagnoses. Some authors have suggested simply averaging the scores by informant (Achenbach, 1995; Piacentini, Cohen, \& Cohen, 1992). 
In an effort to mimic clinical judgement in epidemiological studies, others have suggested schemes adopting a "best estimate" approach (Hart, Lahey, Loeber, \& Hanson, 1994), or relying on conditional pathways in order to integrate information from different sources (Reich \& Earls, 1987). Yet another common approach is to conduct a separate analysis for each informant (Rutter, Cox, Tupling, Berger, \& Yule, 1975; Verhulst, Koot, \& Berden, 1990). The limitation of this strategy is that it is difficult to test the differences between informant-specific results obtained from separate analyses. Due to the limited agreement between informants, the results obtained from different models may be inconsistent and difficult to interpret.

Many studies have used a multiple trait, multiple method model such as structural equation modeling to examine the factor structure and interpretation of data from multiple informant data (Fergusson, 1997; Fergusson \& Horwood, 1987, 1989; Greenbaum, Dedrick, Prange, \& Friedman, 1994). These models assume that measures of child behaviors are likely to reflect three sources of variation: behavioral trait variation, method (or informant) variation, and random errors of measurement. The contribution of each of the three sources of variance to the child's behaviors can be estimated. Using structural equation modeling, one can assess the dimensionality using confirmatory factor analysis (Joreskog, 1969; Muthen, 1984). A small and prespecified number of latent variables are viewed as generating responses to a larger set of items (or multiple indicators). One can estimate the correlation among the latent variables and study correlates of those latent variables. The latent variables are "true" levels of outcomes as discerned by each informant. However, the method is limited to a continuous outcome and does not allow for missing data. We adopt an alternative analytic approach that is flexible in allowing missing data, and that can be readily extended to include nested structures, for example, the case in which children are nested within neighborhoods and schools.

Fitzmaurice et al. (1995) described an approach to integrate data from parents and teachers into a bivariate logistic regression model. This new method allows one to retain complete information from each source and to assess the informant-risk factor interactions as well as "overall" risk factor effects. In addition, it provides measures of association between the informants and adjusts for the association between the responses in the analysis. An additional advantage is the possibility of incorporating missing data on a subset of informants, which addresses the problem of participation bias (La Greca \& Silverman, 1993). Similarly, Raudenbush, Brennan, and Barnett (1995), and Barnett, Raudenbush, Brennan, Pleck, and Marshall (1995) studied husband and wife reports of marital quality and psychological distress using a hierarchical linear model (HLM) (Bryk \& Raudenbush, 1992). In this case, the outcomes were constructed as continuous scales, but the object of studying informant effects and informant-covariate interactions was similar.

HLM has the following three advantages. First, it can incorporate data which is missing at random (MAR) and thus improve the statistical estimation using all available data (Little \& Rubin, 1987). In this way, HLM minimizes the fraction of missing information, which increases the robustness of the findings (Schafer, 1997). Second, HLM can readily be expanded to incorporate the nesting of participants within higher-order settings. Although we forego this option for simplicity's sake in this presentation, extension to incorporating the nested neighborhood effects given the design of our study is straightforward within HLM. Third, HLM is flexible in allowing the data supplied by informants to be binary, ordinal, or multinomial responses.

\section{Exposure to Violence}

Recent studies show a high prevalence of exposure to violence (ETV) in children and adolescents (Bell \& Jenkins, 1993; Furlong, 1994; O’Keefe, 1997; Osofosky, 1995; Osofosky, Wewer, Hann, \& Fick, 1993; Richters \& Martinez, 1993). Symptoms of post-traumatic stress disorder have been found to be highly associated with exposure to violence (Dyson, 1990; Fitzpatrick \& Boldizar, 1993; Singer, Anglin, Song, \& Lunghofer, 1995). Measuring parent and child's reports on exposure to violence can be compared to measuring child's psychiatric symptoms. Both assessments measure a construct at the individual level and obtaining the information from multiple sources is believed to increase validity.

To assess the events of children's ETV objectively is challenging, and discrepancies between informants can be expected for several reasons. First, similar to contextually driven differences in observing child psychopathology symptoms, the salience of reports of ETV may depend on where the event happens. If the event happens outside the home, parents' knowledge of children's ETV depends on whether children report the event to their parents. Second, the reports of the events may depend on how the event is perceived by the informants and the impact of the event on the children. On the other hand, parents may tend to minimize or even forget those events that happen at home. Children may also distort the event when the experience is harmful to them. Third, informants might remember and recall events differently. For those reasons, it is important to obtain information from multiple sources. It should increase the power to identify children who are at risk of ETV and PTSD through understanding the interaction between the risk factors and informants.

The present study applies HLM to assess the effect of demographic risk factors on ETV as reported by child and primary caretaker. We assess the effects of gender, age, ethnicity, and parental education on ETV and the difference of these effects on ETV between primary caretakers and child participants. Data were collected from both primary caretaker and child participants, as part of the assessment of the Project on Human Development in Chicago Neighborhoods (PHDCN; Earls \& Buka, 1997; National Institute of Justice, 1994). The primary caretaker reports will be labeled parent reports as $92 \%$ of the respondents were biological parents. Reports of children are labeled as self-reports.

\section{Methods}

\section{Subjects}

The study sample is drawn from the first wave of the PHDCN, a multi-cohort, multi-level longitudinal study on the determinants of antisocial behavior, substance abuse, and ETV. The sample was obtained from a two-stage design. At the first stage, a stratified random sample of 80 neighborhood clusters was selected from the 343 neighborhood clusters that constitute the city of Chicago. Sampson, Raudenbush, and Earls (1997) describe construction of these neighborhood clusters and the 
Table 1

Demographic Characteristics of the Study Sample $(N=$ 2022)

\begin{tabular}{lc}
\hline Characteristics & $N(\%)$ \\
\hline Cohort & \\
9 years old & $719(35.6 \%)$ \\
12 years old & $719(35.6 \%)$ \\
15 years old & $584(28.9 \%)$ \\
Gender & \\
Boys & $1009(50.1 \%)$ \\
Girls & $1013(49.9 \%)$ \\
Ethnicity & \\
African-American & $723(35.8 \%)$ \\
Hispanic & $861(42.6 \%)$ \\
White & $438(21.6 \%)$ \\
Parental education & \\
$\quad<$ High school & $481(23.8 \%)$ \\
Some high school & $415(20.5 \%)$ \\
Completed high school & $257(12.7 \%)$ \\
Some > high school & $675(33.4 \%)$ \\
Completed college & $194(9.6 \%)$ \\
\hline
\end{tabular}

stratification in some detail. With each sampled cluster, a simple random sample of households was screened and all children within 6 months of their 9th, 12th, or 15th birthday were selected for participation. The response rate from the first wave of PHDCN is $75 \%$.

There are 2022 children aged $8.1-16.4$ years with complete ETV measures for either parent report or self-report in the first wave of the PHDCN survey. These include 1880 self-reports and 1776 parent reports. Among the study sample, 1634 have both parent and self-reports, 246 have self-reports only, and 142 have parent reports only.

Table 1 displays the demographic characteristics of the sample. The study sample is distributed across three of the study's age cohorts, which were initially recruited at 3-year intervals, $33.8 \%$ in the age 9 cohort, $34.9 \%$ in the age 12 cohort, and $31.3 \%$ in the age 15 cohort. The sample is composed of $50.2 \%$ boys and $49.8 \%$ girls. The distributions for the three ethnic groups are $36.8 \%$ African-American, $41.1 \%$ Hispanic, and $21.8 \%$ White. Nearly $58 \%$ of the parents completed high school.

\section{Measure}

Exposure to violence (ETV). The ETV instrument is adapted from the most widely used measure of exposure to violence (Richters \& Saltzman, 1990) to assess the participant's experience of exposure to four different types of violent acts. These include: seeing someone shoved, kicked, or punched; seeing someone attacked with a knife; hearing a gunshot; and seeing someone shot. This measure has been adapted to include questions that assess the location and frequency of such events, as well as the identification of victim(s) and/or perpetrator(s), and the child's relationship to that person (e.g. parent, friend, sibling, etc.) (Selner-O'Hagan, Kindlon, Buka, Raudenbush, \& Earls, 1998)

There is relative lack of information on the psychometric properties of existing ETV instruments and lack of consensus on how ETV measures are scored (Selner-O'Hagan et al., 1998). Based on the wave one ETV measure of the PHDCN, a 10-item scale on direct and indirect witnessing of violence has been developed. As shown in Table 2, it includes direct witnessing of specific events, items on friend and family members being hurt/killed by violent acts, and items on whether the child knew the victim of the witnessed acts. The scale showed adequate validity and reliability (Mohler, Kuo, Kindlon, Buka, \& Earls, 1999). In our analysis, the reliability for each of the informants is .87. A total ETV score was obtained by summing up all of the 10 items.

\section{Procedures}

The ETV interview was administered to both primary caretakers and child participants in the first year of data collection. The measure was part of a comprehensive protocol that included questions related to family demographic characteristics, family functioning, and child behavior. All interviews were conducted in the participant's homes with efforts taken to ensure privacy and protect confidentiality. For the purpose of this study, only children who have complete data on 10 items for either self-report or parent report are included in the analysis.

\section{Analytic Approach: Hierarchical Linear Model for Paired Informants}

Hierarchical linear models (HLM; Bryk \& Raudenbush, 1992; Golstein, 1995) are widely used in educational, social, and health research to study nested data. Classic examples of nested data structures include students nested within classrooms or schools and patients nested within hospitals. A familiar application of HLM involves a regression model formulated to account for variation between people within each "cluster" (e.g. school or hospital). The coefficients of each cluster's regression equation are then allowed to vary randomly over clusters. For example, Raudenbush and Bryk (1986) studied the association between student social class and student achievement within each of 160 high schools by formulating 160 school-specific regression equations, each with an intercept and a slope that described the association between student social class and achievement. These intercepts and slopes were then viewed as varying over high schools, partly as a function of school characteristics and partly as a function of random effects for each school.

Following Raudenbush and Sampson (1999), the measurement of latent variables can be viewed as a case of nested data. Multiple item responses are "nested" within each person. A regression equation within each person specifies the association between each item response and a latent variable of interest. The latent variables are, in fact, regression coefficients that vary randomly over persons. The residuals of this model represent

Table 2

Items of Exposure to Violence

\begin{tabular}{ll}
\hline Items & \multicolumn{1}{c}{ Category } \\
\hline 1. Any family member been hurt by a violent act & $0:$ no, $1:$ yes \\
2. Any friend been hurt by a violent act & $0:$ no, $1:$ yes \\
3. Any friend been killed by a violent act & $0:$ no, $1:$ yes \\
4. Seen someone been shoved/kicked/punched & $0:$ no, $1: 1-10,2:>10$ \\
5. Seen someone attacked with knife & $0:$ no, $1: 1,2:>1$ \\
6. Heard gunshot & $0:$ no, $1: 1-10,2:>10$ \\
7. Seen someone shot & $0:$ no, $1: 1,2:>1$ \\
8. Know victim shoved/kicked/punched & $0:$ no, $1:$ yes \\
9. Know victim attacked by knife & $0:$ no, $1:$ yes \\
10. Know victim shot & $0:$ no, $1:$ yes \\
\hline
\end{tabular}


errors of measurement assumed to be independent. It is straightforward, using this method, to estimate the variance of each latent variable, the correlation between them, and the association between each of these latent variables over covariates.

In the current example, the latent variables are the true levels of ETV as perceived by each informant. The items are the response of each informant to specific questions about violent events that the child has witnessed. Covariates include gender, age, ethnicity, and parent education. We are interested in the variance between children in each latent variable, the correlation between them, and the extent to which covariates have similar associations with each latent variable.

This analytic approach has several strengths: first, it retains all available information about ETV for each informant, even when data are missing on some items or one informant. Second, it can be used to test the hypothesis that the risk factors vary significantly in their effects on ETV as a function of the informant (parent vs. self-report). Third, it adjusts the estimated correlation between informants for measurement error and missing data. Appendix A spells out the approach in detail.

\section{Two Traditional Approaches on Multiple Informants}

In the analysis, we also compare the results of HLM with two traditional approaches used to handle multiple informants. One approach is to conduct a separate regression analysis for each informant, the other approach is to take an average score of ETV from parent and self-reports, then to perform a single regression analysis.

\section{Results}

The results of multivariate HLM using both parent reports and self-reports are presented to assess the effects of gender, age, ethnicity, and parental education on children's ETV. As a comparison, additional results using two more traditional approaches to handle multiple informants are presented as well.

\section{Descriptive Statistics}

Overall, the ETV scores obtained from self-reports are higher than those from parent reports. The mean ETV score for parent reports is $2.97 \pm 2.56$ whereas the mean for the self-reports is $4.20 \pm 3.02$. The coefficient of agreement between parent and self-reports as measured by Pearson correlation is reported by gender and cohort in Table 3. The overall correlation is .43 and this correlation increases to .48 after adjusting for measurement error and missing data obtained from hierarchical

Table 3

Correlations between Parent Reports and Self-reports

\begin{tabular}{|c|c|c|}
\hline Cohort & Boys & Girls \\
\hline 9 year & .37 & .46 \\
\hline 12 year & .42 & .41 \\
\hline 15 year & .36 & .48 \\
\hline Overall & & \\
\hline
\end{tabular}

The overall correlation increases to .48 after adjusting for measurement errors.

All of the correlations are significant, $p=.0001$. linear model. For girls, slightly higher agreement between self-reports and parent reports is found, compared to boys, except for the 12-year cohort.

\section{The Effects of Gender, Age, Ethnicity, and Parental Education on ETV}

Table 4 shows the results from multivariate HLM with gender, age, ethnicity, and parental education as significant predictors of ETV for parent and self-report. The results reveal a significant gender effect on ETV for self-reports but not for parent reports. For self-reports of ETV, boys report .53 higher ETV than do girls. For parent reports, there is no significant gender difference on ETV. Multivariate hypothesis testing shows that the coefficients of gender for the two informants are significantly different, $t=-3.23$.

The HLM results show that ETV increases with age for both parent reports and self-reports. The ETV score increases at .14 per year of age for parent reports and at .51 per year of age for self-reports. Thus, children and adolescents report a greater increase in ETV by age. Multivariate hypothesis testing shows that the age effects on ETV for the two informants are significantly different, $t=-13.65$. The increase in ETV by age is stronger for self-reports than for parent reports.

When the effects of ethnicity on ETV were first examined, using Whites as a reference group, AfricanAmericans had significantly higher ETV scores for both parent reports and self-reports than did Whites. Hispanics had lower ETV scores than did Whites for both parents and self-reports. A multivariate hypothesis testing showed that there is no significant difference for the African-Americans, $t=-1.52$. Therefore, the coefficients of African-Americans were constrained to a single estimate. A pooled coefficient with decreased standard error for both informants was obtained after being constrained. For Hispanics, multivariate hypothesis testing showed that the coefficients on parent reports and self-reports are significantly different, $t=-4.87$. The tendency of ETV to be lower for Hispanics than for Whites is more pronounced in the parent reports than it is for the self-reports.

For parent reports, the effect of parental education on ETV is not significant but for self-reports there is a significantly negative association. Children with lower parental education report higher ETV. Multivariate hypothesis testing shows that the coefficients on parent reports and self-reports are significantly different, $t=$ 4.63.

\section{The Results Using Traditional Approaches}

Table 5 shows the results from two traditional approaches. Compared with the results from the HLM multivariate model in Table 4, the coefficients from two separate regression models are quite similar but the standard errors are smaller for HLM multivariate models that exploit the correlation between informants. We were not able to perform statistical tests on the difference between the two sets of coefficients from separate regression models, a key disadvantage of that method.

A second approach is to take the average score of ETV from parent reports and self-reports and conduct a single regression model. Compared with the HLM model, the 
Table 4

Coefficients of Predicting ETV for Parent Reports and Self-reports Derived from HLM Model

\begin{tabular}{|c|c|c|c|}
\hline & \multicolumn{2}{|c|}{$\begin{array}{c}\text { Coefficient(SE) } \\
{[p \text {-value }]}\end{array}$} & \multirow{2}{*}{$\begin{array}{c}\text { Multivariate } \\
\text { hypothesis } \\
\text { testing } \\
t^{\mathrm{a}}\end{array}$} \\
\hline & Parent & Self & \\
\hline Intercept & \multicolumn{2}{|c|}{$\begin{array}{c}2.049^{\mathrm{b}}(0.184) \\
{[<.0005]}\end{array}$} & - \\
\hline \multicolumn{4}{|l|}{ Gender } \\
\hline Girl (reference group) & - & - & - \\
\hline Boy & $\begin{array}{c}0.116(0.107) \\
{[.276]}\end{array}$ & $\begin{array}{c}0.533(0.116) \\
{[<.0005]}\end{array}$ & -3.23 \\
\hline $\mathrm{Age}^{\mathrm{c}}$ & $\begin{array}{c}0.138(0.022) \\
{[<.0005]}\end{array}$ & $\begin{array}{c}0.513(0.023) \\
{[<.0005]}\end{array}$ & -13.65 \\
\hline \multicolumn{4}{|l|}{ Ethnicity } \\
\hline $\begin{array}{l}\text { White (reference group) } \\
\text { African-American }\end{array}$ & \multicolumn{2}{|c|}{$\begin{array}{c}1.858^{\mathrm{d}}(0.124) \\
{[<.0005]}\end{array}$} & - \\
\hline Hispanic & $\begin{array}{c}-0.642(0.142) \\
{[<.0005]}\end{array}$ & $\begin{array}{c}-0.0469(0.149) \\
{[.753]}\end{array}$ & -4.87 \\
\hline Parental education & $\begin{array}{c}0.0445(0.041) \\
{[.279]}\end{array}$ & $\begin{array}{c}-0.106(0.0427) \\
{[.013]}\end{array}$ & 4.63 \\
\hline \multicolumn{4}{|c|}{$\begin{array}{l}{ }^{\mathrm{a}} t>0 \text { if parent report }>\text { self-report. } \\
{ }^{\mathrm{b}} \text { The intercept was constrained to a pooled estimate: the intercept was } 2.15 \text { for parent report and } \\
1.92 \text { for self-report before constrained; multivariate hypothesis testing shows no difference between } \\
\text { informants }(t=.86) \text {. } \\
\left.{ }^{\mathrm{c}} \text { Actual age (range } 8.1-16.4\right) \text { centered at } 9 \text { years old is used in the analysis. } \\
{ }^{\mathrm{a}} \text { The coefficient was constrained to a pooled estimate; the coefficient was } 1.73 \text { for parent report } \\
\text { and } 2.01 \text { for self-report before constrained; multivariate hypothesis testing shows no difference } \\
\text { between informants }(t=-1.52) \text {. }\end{array}$} \\
\hline
\end{tabular}

Table 5

Regression Coefficients of Traditional Methods Derived from Separate and Combined Models

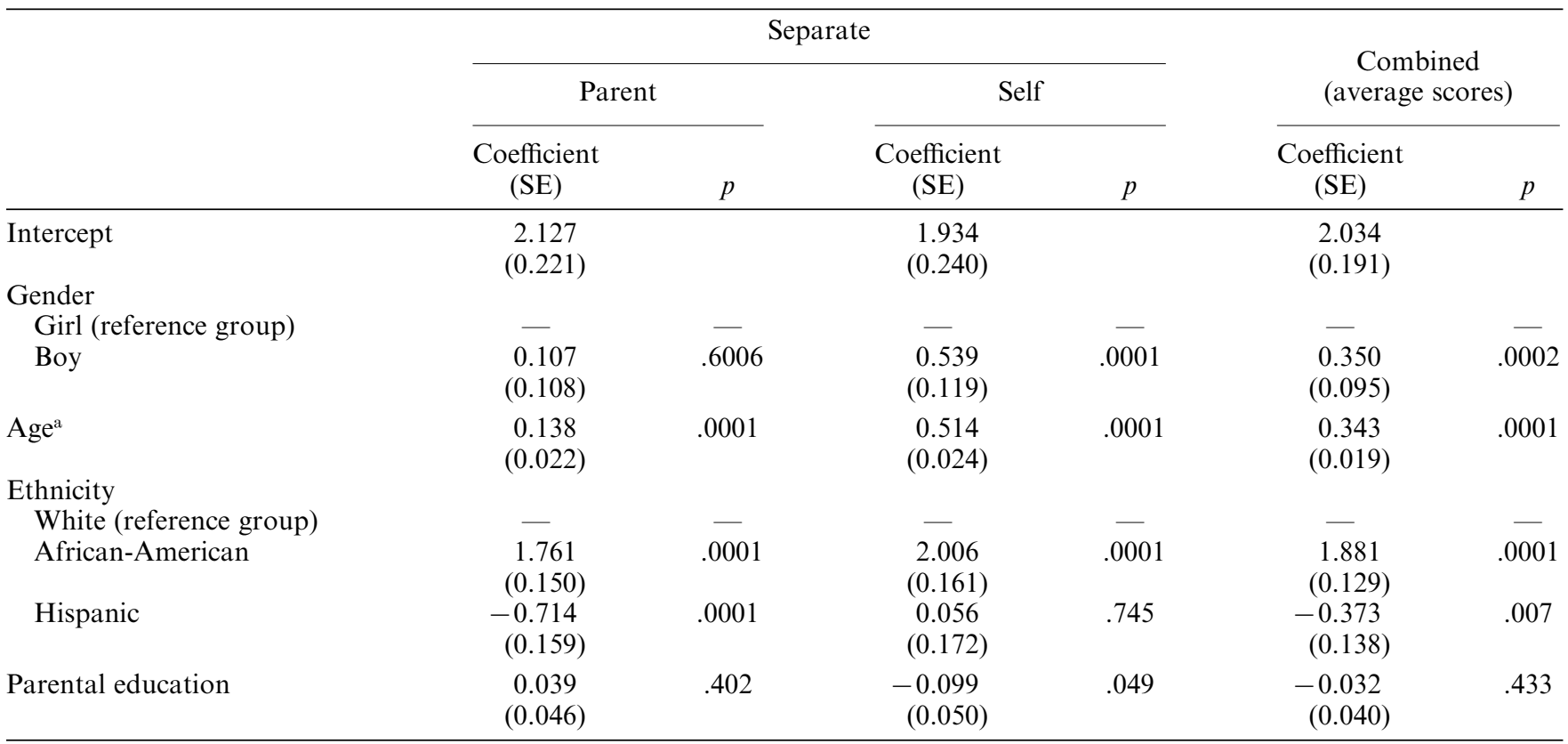

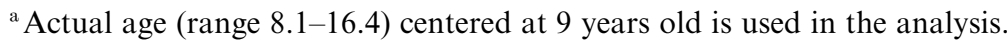

coefficients using mean ETV scores are about the average of two separate coefficients obtained from parent reports and self-reports. Notice that the coefficient for parental education is -.032 , which becomes nonsignificant due to the opposite effects of parental education on ETV from parent reports and self-reports. The opposite effects of parental education on ETV by informants, as reported in the HLM as well in the separate regression models, are attenuated using this approach.

\section{Discussion}

\section{Analytic Method for Multiple Informants}

By applying a hierarchical linear model, we are able to utilize all of the information available from both informants in a single statistical model. With this model we can formally test whether associations between risk factors and ETV scores vary between informants. When there is an informant effect, a separate set of estimates for 
each informant can be obtained. In the reported analysis on ETV, there is an informant effect for both gender and age. There is no gender difference on ETV scores for parent reports but one does exist for self-reports. Boys report significantly higher ETV scores than do girls across all ages. These findings of gender differences on ETV based on self-reports are consistent with results from other studies (Fitzpatrick \& Boldizar, 1993; Gladstein, Rusonis, \& Heald, 1992; O'Keefe, 1997). Our findings thus suggest that parents, who generally report lower scores than their children, under-report ETV more strongly for boys.

Both self-reports and parent reports show significant age effects on ETV. That the older children are more likely to have higher ETV scores for both informants supports the construct validity of the scale. The informant effect on age, as reported in our results, suggests a significantly stronger association between age and ETV for self-reports than for parent reports. These findings show that older children may not only have more ETV, but more exposure outside the home environment that is less likely to be observed by the parents. We might assume a similar reason for the stronger under-reporting of ETV by parents for boys compared to girls, since boys may spend more time than girls outside the home environment.

The analysis provides important statistical information on how the association between risk factor and outcome differs by informants. On the other hand, when there is no informant-risk interaction, a pooled parameter estimate can be obtained for both informants and the standard error is smaller compared to the standard error obtained from separate regressions. For example, it has been shown that compared with Whites, African-Americans are more likely to have higher exposure to violence scores for both parent and self-reports. Since the multivariate hypothesis test shows that there is no significant difference for these two coefficients, we can estimate a pooled coefficient for both informants.

Comparing our results from the HLM with traditional approaches, we agree with Offord et al. $(1989,1996)$ and others (Angold et al., 1987; Edelbrock et al., 1986) that the information obtained from different sources should not be combined and should not be averaged. Our analyses show that the traditional approach of dealing with information obtained from multiple informants by taking the average score from different informants can be misleading. For example, the results suggest that children with higher parental education show higher ETV on the parent reports but lower ETV on the self-reports. Combining the information by taking the average scores from parent and self-reports attenuates this association as shown in Table 5. Given differences in reliability and validity (Edelbrock et al., 1986; Hart et al., 1994; RubioStipec et al., 1994; Verhulst et al., 1987), it might be reasonable to use only parent reports for younger children and self-reports for older adolescents. Nonetheless, some important information might be lost by using only single informants.

As shown in our result, the coefficients obtained from HLM did not differ substantially from the traditional approach of conducting separate analyses. However, only through integrating the two informants are we able to test differences statistically between informants. Our recommended approach provides a way of evaluating the tenability of combined versus separate analysis and gives us a way of proceeding when the results suggest that neither approach is optimal. To the extent the two reporters give similar information, the analysis capitalizes on this similarity to strengthen statistical precision; to the extent the two reporters give different results, the method accommodates these differences. We thus avoid the forced choice (combined vs. separate), using the strengths of each to the extent justified by the data.

\section{Conclusion}

The main purpose of this paper is to investigate whether informant reports differ, how they differ, and how best to analyze data from multiple informants. We demonstrate the analytic method using a hierarchical linear model that incorporates information obtained from multiple informants. In the illustrative analysis, only gender, age, ethnicity, and mother's education were included as risk factors for ETV. In order to derive more satisfying results, other variables known to be related to children's ETV should be included, such as income level, marital status, and living arrangements and type of residence (Gladstein et al., 1992; O'Keefe, 1997; Richters \& Martinez, 1993). Our study shows that assessing children's exposure to violence leads to different results by informants. The results also demonstrate that it is possible to use information from different sources in a multivariate statistical model. This application of HLM underscores the strengths of being able to assess the effect of risk factors and the interactions between risk factors and informants. The findings of the study support the use of a hierarchical linear model where information obtained from different sources is being integrated but not crudely combined, as in traditional approaches.

Acknowledgements - The Project on Human Development in Chicago Neighborhoods is supported by the funding from the MacArthur Foundation, the National Institute of Justice, and the National Institute of Mental Health. Dr Kuo is supported by a post-doctoral fellowship from PHDCN and Dr Mohler is supported by the Swiss National Science Foundation (No. 3233-47725.96).

Thanks are due to Steven Buka for his essential role in the PHDCN, to Robert Brennan for his suggestion on the presentation of the result, to Richard Congdon for the programming of HLM, and to Kathy McGraffigan for the preparation of the data.

\section{References}

Achenbach, T. M. (1995). Diagnosis, assessment, and comorbidity in psychosocial treatment research. Journal of Abnormal Child Psychology, 23, 45-65.

Achenbach, T. M., McConaughy, S. H., \& Howell, C. T. (1987). Child/adolescent behavioral and emotional problems: Implications of cross-informant correlations for situational specificity. Psychological Bulletin, 101, 213-232.

Andrews, V. C., Garrison, C. Z., Jackson, K. L., Addy, Ch. L., $\&$ McKeown, R. E. (1993). Mother-adolescent agreement on symptoms and diagnoses of adolescent depression and conduct disorders. Journal of the American Academy of Child and Adolescent Psychiatry, 32, 731-738.

Angold, A., Weissmann, M. M., John, K., Merikangas, K. R., Prusoff, B. A., Wickramaratne, P., Gammon, G. D., \& Warner, V. (1987). Parent and child reports of depressive symptoms in children at low and high risk of depression. Journal of Child Psychology and Psychiatry, 28, 901-915.

Barnett, R. C., Raudenbush, S. W., Brennan, R. T., Pleck, J. H., \& Marshall, N. J. (1995). Change in job and marital experiences and change in psychological distress: A longi- 
tudinal study of dual-earner couples. Journal of Personality and Social Psychology, 69, 839-850.

Bell, C., \& Jenkins, E. (1993). Community violence and children on Chicago's south side. Psychiatry: Interpersonal and Biological Processes, 56, 46-54.

Bryk, A., \& Raudenbush, S. W. (1992). Hierarchical linear models in social and behavioral research: Applications and data analysis methods. Newbury Park, CA: Sage Publications.

Dyson, J. (1990). The effect of family violence on children's academic performance and behavior. Journal of the National Medical Association, 82, 17-22.

Earls, F., \& Buka, S. (1997). A research report from the Project on Human Development in Chicago Neighborhoods from the National Institute of Justice. Technical Report. U.S. Department of Justice.

Edelbrock, C., Costello, A. J., Dulcan, M. K., Calabro, C. N., \& Kala, R. (1986). Parent-child agreement on child psychiatric symptoms assessed via structured interview. Journal of Child and Adolescent Psychiatry, 27, 181-190.

Fergusson, D. M. (1997). Annotation: Structural equation models in developmental research. Journal of Child Psychology and Psychiatry, 38, 877-887.

Fergusson, D. M., \& Horwood, L. J. (1987). The trait and method components of ratings of conduct disorder. Part I. Maternal and teacher evaluations of conduct disorder in young children. Journal of Child Psychology and Psychiatry, 28, 249-260.

Fergusson, D. M., \& Horwood, L. J. (1989). Estimation of method and trait variance in ratings of conduct disorder. Journal of Child Psychology and Psychiatry, 30, 365-378.

Fitzgerald, H. E., Zucker, R. A., Maguin, E. T., \& Reider, E. E. (1994). Time spent with child and parental agreement about preschool children's behavior. Perceptual and Motor Skills, 79, 336-338.

Fitzmaurice, G. M., Laird, N. M., Zahner, G. E. P., \& Daskalakis, C. (1995). Bivariate logistic regression analysis of childhood psychopathology ratings using multiple informants. American Journal of Epidemiology, 142, 1194-1203.

Fitzpatrick, K. M., \& Boldizar, J. P. (1993). The prevalence and consequences of exposure to violence among AfricanAmerican. Journal of the American Academy of Child and Adolescent Psychiatry, 32, 424-430.

Furlong, M. (1994). School violence and safety in perspective. School Psychology Review, 23, 139-150.

Gladstein, J., Rusonis, E. J., \& Heald, F. P. (1992). A comparison of inner-city and upper-middle class youths' exposure to violence. Journal of Adolescent Health, 13, 275-280.

Goldstein, H. (1995). Hierarchical data modeling in the social sciences. Journal of Educational and Behavioral Statistics, 20, 201-204.

Greenbaum, P. E., Dedrick, R. F., Prange, M. E., \& Friedman, R. M. (1994). Parent, teacher, and child ratings of problem behaviors of youngsters with serious emotional disturbances. Psychological Assessment, 6, 141-148.

Hart, E. L., Lahey, B. B., Loeber, R., \& Hanson, K. S. (1994). Criterion validity of informants in the diagnosis of disruptive behavior disorders in children: A preliminary study. Journal of Consulting and Clinical Psychology, 62, 410-414.

Joreskog, K. G. (1969). A general approach to confirmatory factor analysis. Psychometrica, 34, 183-202.

La Greca, A. M., \& Silverman, W. K. (1993). Parent reports of child behavior problems: Bias in participation. Journal of Abnormal Child Psychology, 21, 89-101.

Little, R. J. A., \& Rubin, D. B. (1987). Statistical analysis with missing data. New York: John Wiley \& Sons.

Loeber, R., Green, St. M., \& Lahey, B. B. (1990). Mental health professionals' perception of the utility of children, mothers, and teachers as informants on childhood psychopathology. Journal of Clinical Child Psychology, 19, 136-143.

Mohler, B., Kuo, M., Kindlon, D., Buka, S., \& Earls, F. (1999). Developmental variation of reliability and validity of instru- ment of exposure to violence. Presented at the biennial meetings of the Society for Research in Child Development, Albuquerque, April 15 .

Muthen, B. O. (1984). A general structural equation model with dichotomous, ordered, categorical, and continuous latent variable indicators. Psychometrica, 49, 115-132.

National Institute of Justice. (1994). Breaking the cycle: Predicting and preventing crime. A research report on the PHDCN from the National Institute of Justice, U.S. Department of Justice.

Offord, D. R., Boyle, M. H., \& Racine, Y. (1989). Ontario Child Health Study: Correlates of disorder. Journal of the American Academy of Child and Adolescent Psychiatry, 28, 856-860.

Offord, D. R., Boyle, M. H., Racine, Y., Szatmari, P., Fleming, J. E., Sanford, M., \& Lipman, E. L. (1996). Integrating assessment data from multiple informants. Journal of the American Academy of Child and Adolescent Psychiatry, 35, 1078-1085.

O'Keefe, M. (1997). Adolescents' exposure to community and school violence: Prevalence and behavioral correlates. Society for Adolescent Medicine, 20, 368-376.

Osofosky, J. (1995). The effects of exposure to violence on young children. American Psychologist, 50, 782-788.

Osofosky, J., Wewer, S., Hann, D., \& Fick, A. (1993). Chronic community violence: What is happening to our children? Psychiatry: Interpersonal and Biological Processes, 56, 36-45.

Phares, V. (1996). Accuracy of informants: Do parents think that mother knows best? Journal of Abnormal Child Psychology, 25, 165-171.

Piacentini, J. C., Cohen, P., \& Cohen, J. (1992). Combining discrepant diagnostic information from multiple sources: Are complex algorithms better than simple ones? Journal of Abnormal Child Psychology, 20, 51-63.

Raudenbush, S. W., Brennan, R. T., \& Barmett, R. C. (1995). A multivariate hierarchical model for studying psychological change within married couples. Journal of Family Psychology, 9, 161-174.

Raudenbush, S. W., \& Bryk, A. S. (1986). A hierarchical model for studying school effects. Sociology of Education, 59, 1-17.

Raudenbush, S. W., Rowan, B., \& Kang, S. J. (1991). A multilevel multivariate model for school climate and estimation via the EM Algorithm and application to U.S. high school data. Journal of Education Statistics, 1, 295-330.

Raudenbush, S. W., \& Sampson, R. J. (1999). Ecometrics: Toward a science of accessing ecological settings, with application to the systematic social observation of neighborhoods. Sociological Methodology, 29, 1-41.

Reich, W., \& Earls, F. (1987). Rules for making psychiatric diagnosis in children on the basis of multiple sources of information: Preliminary strategies. Journal of Abnormal Child Psychology, 15, 601-616.

Richters, J., \& Saltzman, W. (1990). Survey of children's exposure to community violence: Parent report. Rockville, MD: National Institute of Mental Health.

Richters, J. E., \& Martinez, P. (1993). The NIMH community violence project: I. Children as victims and witnesses to violence. Psychiatry, 56, 7-21.

Rubio-Stipec, M., Canino, G. J., Shrout, P., Dulcan, M., Freeman, D., \& Bravo, M. (1994). Psychometric properties of parent and children as informants in child psychiatry epidemiology with the Spanish diagnostic interview schedule for children (DISC.2). Journal of Abnormal Child Psychology, 22, 703-720.

Rutter, M., Cox, A., Tupling, C., Berger, M., \& Yule, W. (1975). Attainment and adjustment in two geographical areas. I. The prevalence of psychiatric disorder. British Journal of Psychiatry, 126, 493-509.

Sampson, R., Raudenbush, S., \& Earls, F. (1997). Neighborhood and violent crime: A multi-level study of collective efficacy. Science, 277, 918-924. 
Schafer, J. L. (1997). Analysis of incomplete multivariate data. London: Chapman \& Hall.

Selner-O'Hagan, M. B., Kindlon, D. L., Buka, S. L., Raudenbush, S. W., \& Earls, F. J. (1998). Assessing exposure to violence in urban youth. Journal of Child Psychology and Psychiatry, 39, 215-224.

Singer, M. I., Anglin, T. M., Song, L., \& Lunghofer, L. (1996). Adolescents' exposure to violence and associated symptoms of psychological trauma. Journal of American Medical Association, 273, 477-482.

Verhulst, F. C., Althaus, M., \& Berden, G. F. M. G. (1987). The Child Assessment Schedule: Parent-child agreement and validity measures. Journal of Child Psychology and Psychiatry, 28, 455-466.

Verhulst, F. C., Koot, H. M., \& Berden, G. F. (1990). Fouryear follow-up of an epidemiological sample. Journal of the American Academy of Child and Adolescent Psychiatry, 29, 440-448.

Verhulst, F. C., \& Van der Ende, J. (1992). Agreement between parents' reports and adolescents' self-reports of problem behavior. Journal of Child Psychology and Psychiatry, 33, 1011-1023.

Manuscript accepted 10 April 2000

\section{Appendix A}

To analyze information obtained from two different informants, a two-level hierarchical linear model with multivariate outcomes was employed. In order to illustrate the application of the method on information on ETV, gender, age, ethnicity, and parental education were used as possible risk factors.

Since each pair of parent and self-reports on ETV represents the same child, they are certain to be correlated with one another. Hierarchical linear models have been adapted for use with such multivariate outcomes (Raudenbush, Rowan, \& Kang, 1991).

The level 1, or within-person model postulates that the outcome score is the ETV score plus a measurement error. The model is written as followed:

$$
Y_{i j}=(\mathrm{P})_{\mathrm{ij}}\left(\pi_{p j}+e_{p i}\right)+(\mathrm{S})_{\mathrm{ij}}\left(\pi_{s j}+e_{s i}\right) .
$$

In this case, $Y_{i j}$ is the ETV score for participant $\mathrm{j}$ at occasion $\mathrm{i},(\mathrm{P})_{\mathrm{ij}}$ is an indicator variable taking on a value of 1 if the ETV score is obtained from parent report and 0 if the ETV score is obtained from self-report; $(\mathrm{S})_{\mathrm{ij}}$ takes on a value of 1 for selfreport and 0 for parent report. The measurement errors $e_{p i}$ and $e_{s i}$ are assumed independently, normally distributed with variances $\sigma_{\mathrm{pi}}{ }^{2}$ and $\sigma_{\mathrm{si}}{ }^{2}$, respectively. These two variances are estimated from a separate item analysis and assumed known here. The ETV scale is the sum of the 10 item scores and the error variance is the pooled, within-person variance of these 10 item scores.

If a participant has both reports, the model has two equations, where the first occasion involves the parent report and the second occasion the self-report:

$$
\begin{aligned}
& Y_{1 j}=(1)\left(\pi_{p j}+e_{p i}\right)+(0)\left(\pi_{s j}+e_{s i}\right)=\pi_{p j}+e_{p i}, \\
& Y_{2 j}=(0)\left(\pi_{p j}+e_{p i}\right)+(1)\left(\pi_{s j}+e_{s i}\right)=\pi_{s j}+e_{s i} .
\end{aligned}
$$

However, suppose the data includes only the parent report, then the model for participant $\mathrm{j}$ would be:

$$
Y_{1 j}=(1)\left(\pi_{p j}+e_{p i}\right)+(0)\left(\pi_{s j}+e_{s i}\right)=\pi_{p j}+e_{p i} .
$$

But if only the self-report were available, the model for participant $\mathrm{j}$ would be:

$$
Y_{2 j}=(0)\left(\pi_{p j}+e_{p i}\right)+(1)\left(\pi_{s j}+e_{s i}\right)=\pi_{s j}+e_{s i} .
$$

We assume the error terms $e_{p i}$ and $e_{s i}$ to fulfill the assumptions $e_{p i} \sim \mathrm{N}\left(0, \sigma_{\mathrm{p}}^{2}\right)$ and $e_{s i} \sim \mathrm{N}\left(0, \sigma_{\mathrm{s}}^{2}\right)$. Therefore, the model has the advantage of being able to retain those child participants who have either self-report or parent report.

The level 2 model, or between-person model including gender, age, ethnicity, and parental education as predictors looks as follows:

$$
\begin{aligned}
\pi_{p j}= & \beta_{10}+\beta_{11}\left(\text { (gender }_{j}+\beta_{12}(\text { age })_{j}+\beta_{13}(\text { African-American })_{j}\right. \\
& +\beta_{14}(\text { Hispanic })_{j}+\beta_{15}(\text { Education })_{j}+r_{p j} \\
\pi_{s j}= & \beta_{20}+\beta_{21}(\text { (gender })_{j}+\beta_{22}(\text { age })_{j}+\beta_{23}(\text { African-American })_{j} \\
& +\beta_{24}(\text { Hispanic })_{j}+\beta_{25}(\text { Education })_{j}+r_{s j},
\end{aligned}
$$

Above, $\beta_{10}$ and $\beta_{20}$ are the level 2 intercepts for each of the two true score estimates $\left(\pi_{\mathrm{p}}\right.$ and $\left.\pi_{\mathrm{s}}\right) ; \beta_{1 \mathrm{q}}$ and $\beta_{2 \mathrm{q}}(\mathrm{q}=1,2, \ldots, 5)$ are level two coefficients predicting each of the two ETV true score estimates. Gender, age, ethnicity, and parental education are predictors for each child participant. It should be noted that the equations predicting each of the outcomes are parallel in our analysis. We assume the random effects $r_{p j}$ and $r_{s j}$ are normally distributed with variance $\tau_{p p}, \tau_{s s}$ and covariance $\tau_{p s}$.

When the level 2 model (equation 2 and 3 ) is substituted into a level 1 model (equation 1), the result is the mixed linear model (Bryk \& Raudenbush, Chapter 3, 1992). The parameters of this model are estimated simultaneously via maximum likelihood.

Using the multivariate hypothesis testing procedure of the HLM program, the difference between self-report and parent report for each predictor can be tested as followed:

$$
H_{0}: \beta_{1 \mathrm{q}}=\beta_{2 \mathrm{q}} .
$$

If the effect of a predictor on ETV does not vary by informants $\left(\beta_{1 \mathrm{q}}=\beta_{2 \mathrm{q}}\right)$, a single coefficient may be estimated for both informants. 